\title{
THEMATIC PAPER \\ Mental health reform in Fiji and opportunities for training assistance
}

\author{
M. Parameshvara Deva
}

Professor of Psychiatry. Faculty of Medicine and Health Sciences, University Tunku Abdul Rahman, Sg Long Campus, Ceras, Malaysia, email parameshvara@ utar.edu.my
Fiji inherited a British colonial healthcare system. In 2010 the long dormant mental health law was replaced by the Mental Health Decree (MHD), which set up divisional mental health units for the purpose of managing mental health problems outside of the old asylum. The Ministry of Health recruited an overseas consultant to help improve training. Under the MHD, stress management wards, stress management clinics and stress management day centres have been set up, to decentralise and deinstitutionalise psychiatric care. These are on the whole doing reasonably well and have good client acceptance.

The Western Pacific region is home to 16 countries, from Papua New Guinea in the west to the Cook Islands in the east. Among these island countries, Fiji is the second largest in terms of population, after Papua New Guinea. Fiji is a Melanesian tropical island nation of $18274 \mathrm{~km}^{2}$ and over 332 islands situated in the Western Pacific, about $2000 \mathrm{~km}$ north-east of New Zealand. Only 110 or so of the islands have permanent residents. Fiji has been inhabited for at least 5000 years. Today, the population numbers around 865000 , with about $55 \%$ of its people Melanesian and $38 \%$ of Indian origin. Indian migrants were brought in by the British administrators in the 19th century to help develop the sugar industry, which became the mainstay of the economy. There are sizeable numbers of Polynesians from Samoa and Tonga in Fiji and smaller numbers of Chinese and Europeans. Fiji has two large islands where most of the population lives. Viti Levu is the larger of the two and has over three-quarters of the population and most of the industry in Fiji. The capital, Suva, is on the island of Viti Levu. Fiji gained independence in 1970, after 100 years of British rule, and, despite several periods of unrest and military rule, remains a peaceful, beautiful and friendly country which attracts increasingly large numbers of tourists.

Fiji inherited an administrative and healthcare system that was initially set in place by the British and the country continues to maintain that inheritance. The region's first medical school, the Fiji School of Medicine, was founded in 1885 and the first mental asylum, named St Giles, was established in Suva a year earlier.

\section{Health and mental health services in Fiji}

The health services are extensive and cover the numerous islands; the primary care service in particular is of good quality. There are 24 hospitals in Fiji: three divisional hospitals, at Suva, Lautoka and Labasa, which have specialist services; 16 subdivisional hospitals; three area hospitals; and two special hospitals, including the St Giles hospital in Suva, with 136 beds and housing about 90 patients at any one time. Supporting these 24 hospitals are hundreds of health centres and an even larger number of nursing stations, together with numerous village health workers.

There are over 450 doctors, 67 dentists and 1572 nurses in Fiji within all sectors. The Fiji School of Medicine, the Fiji School of Nursing and the School of Public Health are now amalgamated under the Fiji National University (FNU) in Suva. A second medical school exists in association with a private university in Lautoka (the University of Fiji), from which the first set of students graduated in 2013.

Mental health services in Fiji date back to 1884, with the setting up of the St Giles Lunatic Asylum in Suva for the care of four European, four Indian and two Fijian patients. This was probably the first mental hospital in the region and remained much the same, with small numbers of patients, until 1935, when the name was changed to St Giles Mental Asylum. Patient numbers had increased to 227 by 1959. In 1968 psychiatry was added to the formal curriculum of the Fiji School of Medicine. The first psychiatrist in Fiji was Dr D. F. McGregor, who was appointed in 1965. In 1970 the first qualified nurse was appointed to the St Giles hospital. The first Fijian was appointed as a psychiatrist around 1985. The St Giles hospital is situated on a hill overlooking the picturesque city of Suva and the harbour and bay. It consists of mostly old but renovated wooden buildings, with parts added over many years. It possesses a variety of measures for security, reflecting changing trends. The hospital has a boundary with the Suva prison and borders the large Suva cemetery.

Mental health was not initially included in the work of the hospitals, health centres and nursing stations throughout Fiji. Instead, people with a mental illness were routinely transferred at great expense and difficulty to St Giles when they needed evaluation or treatment. It was only in 1995 that the two psychiatrists from St Giles managed to open peripheral psychiatric clinics in some outlying towns, but these functioned only at infrequent intervals.

\section{The 2010 Mental Health Decree}

In 2010, Fiji's mental health law, which had been long dormant, was replaced by the Mental Health 
Decree (MHD), after much discussion. Under the MHD there was provision for the formal setting up of divisional mental health units for the purpose of managing mental health problems outside of the old asylum.

The MHD had a deadline of 1 July 2010 for the implementation of its provisions, but neither the doctors and nurses in mental health work nor those in general hospitals were ready for the paradigm shift that aimed to extend mental healthcare beyond St Giles. Most felt that there was no need for there to be psychiatry beds in general hospitals. They had been taught that patients with a mental illness needed the security of a mental institution where the wards were secure and staff had been trained to deal with violence. Identifying where the new psychiatric wards should go was another major problem, as hospital administrators said they could offer no space for them, citing as the reasons security worries and a lack of space. But the need to implement a government decree finally produced change.

The first ward was opened on 20 May 2011 in Labasa. It was a five-bed ward run by three trained psychiatric nurses, who had been working in nonpsychiatric wards till then, and a medical officer with 1 year's experience at St Giles. It proved to be far less threatening than many had feared. It was called a stress management ward (SMW) in a move to avoid the stigma attached to mental illness.

A second SMW opened in June 2011 at Suva Divisional Hospital. The administration had finally decided to allocate eight beds in a renovated surgical ward for psychiatric use. But the opening of this ward proved more difficult than anticipated, due to administrative problems.

A third SMW, with ten beds, opened in June 2011 in Lautoka Divisional Hospital and was run by a medical officer with a few months' training in St Giles and two trained psychiatric nurses.

The move out of St Giles actually started about 2 months before the first SMW opened when, with the help of the FNU, a stress management clinic (SMC) was started in a primary care centre in Samabula, a suburb of Suva city. This was established largely to provide a facility without the atmosphere of a specialist mental health clinic for those with emotional distress. It also served to teach students and post-basic nursing students about psychiatric problems in primary care. It was run by psychiatrists at the Fiji School of Medicine.

In 2012, after many attempts to start a day psychosocial rehabilitation centre in Suva had failed for lack of space and support, a decision was made to start such a centre at the SMW in Labasa (the most successful of the three SMWs). A grant of $£ 1000$ from the Royal College of Psychiatrists Western Pacific International Division helped to equip this centre. A space next to the hospital was allocated to the SMW for its stress management day programme for psychosocial rehabilitation. The new centre opened in November 2012 and was run with the assistance of a volunteer occupational therapist from Australia.

\section{Training}

A visiting professor of psychiatry from Malaysia was contracted by the FNU to help the Fiji School of Medicine and the associated Faculty of Medicine improve training in psychiatry for medical students and nurses, and to help the FNU establish a postgraduate course to produce psychiatrists for Fiji. An international seminar was held in February 2011 to work out the details of the postgraduate training. Plans were laid for visiting volunteer psychiatrists from overseas to work with the three local psychiatrists. Overseas consultants attending the seminar worked with the two academic staff of the Fiji School of Medicine, as well as with the only psychiatrist at St Giles, and with the College of General Practitioners, in order to produce an outline of the postgraduate teaching programme.

Many discussions were held and it was decided that there should be new training courses to help nurses learn how a general hospital psychiatric ward should function. The establishment of such wards had been stipulated by the MHD. Unfortunately, when the first 2-day training workshop was organised in the divisional hospital in Suva, none of the nurses at that hospital turned up.

In 2012, the Postgraduate Diploma in Mental Health (PGDMH) programme, initially attended by three doctors and three senior nurses, commenced at the FNU. The teaching of these health staff continued to be based primarily at St Giles, despite an earlier intention to move the teaching to an SMW. Plans for overseas psychiatrists to support the local psychiatrists in teaching were not implemented. The training of medical students, nursing students, post-basic nurses in psychiatry (as well as the teaching of the three doctors who had obtained the first batch of PGDMHs) has continued to be based at St Giles, with nominal clinical supervision by the two university teachers.

In 2012 the Fiji Ministry of Health's only psychiatrist resigned. The Ministry had had plans to improve the training of local doctors and nurses in psychiatry (who were all employees of the Ministry), to solve the problems of providing adequate mental healthcare throughout Fiji. Accordingly, the Ministry recruited the overseas consultant who had come in 2011 to the FNU to help improve training, in particular the clinical supervision of clinical trainees and staff. Improvements in supervision at St Giles, at the three SMWs and at over ten outlying clinics were carried out in the following 6 months. The consultant helped recruit a further six trainees for the second PGDMH course in 2013, including the first-ever trainee psychiatrists from the Pacific Island countries of Palau, Kiribati and Vanuatu.

\section{Conclusions}

The move from care based in an old mental institution to mental healthcare outside the institutional model of care was not an easy transition. It was spearheaded by the Fiji Minister of Health himself, despite considerable resistance from professionals 
in the healthcare system. The SMWs and SMCs as well as some stress management day centres that have also been established under the MHD - are on the whole doing reasonably well and have good client acceptance.

The reasons for the resistance to change lie in the fact that the teaching of psychiatry to doctors and nurses had been based for many years at St Giles. The old asylum was the model for mental healthcare, not only for Fiji but also for hundreds of Pacific Islands students. While the rest of medicine was moving forwards in Fiji, the practice of psychiatry had stagnated (arguably by design). The medical students of the Pacific had been trained in the St Giles institutional model of psychiatric care, a venerable mental hospital with locked doors. They had become the consultants and decisionmakers in many Pacific Island countries. Their training in a custodial mental hospital had made an indelible mark on their understanding of what constituted optimal facilities for psychiatric care.

After so much effort, and despite many difficulties, the three SMWs set up under the MHD are now functioning reasonably well. Fiji also has three more diploma-level psychiatrists in the three SMWs and one new medical superintendent at St Giles. The country still lacks occupational therapists, clinical psychologists and social workers. The clinical skills of doctors and nurses and medical students should be improved, and training should be based at the SMWs rather than the mental hospital. Ongoing efforts aim to improve the running of the mental hospital through better ward management, including the separation of patients with acute illnesses from those with forensic problems and intellectual disabilities.

After much debate on the curriculum of the PGDMH, it was felt that the programme needed a review. In an attempt to improve the training of future psychiatrists for Fiji and the region, help from the Royal College of Psychiatrists was sought through the Western Pacific International Division. A request was sent to College members in the region. In early 2013 the overseas consultant, in collaboration with the Western Pacific International Division of the College, drew up a list of over 70 volunteer senior psychiatrists. Most of them were based in Australia and New Zealand. They were keen to help the PGDMH and the nurse training programmes of the FNU. Their names have been submitted to the Ministry of Health and await approval by the FNU.

Meanwhile, the first-ever psychiatrists from the islands of Vanuatu, Palau and Kiribati, who had been trained in the 1-year PGDMH, graduated in 2013 and are now working in their respective countries.

Fiji has come a very long way in changing its pattern of psychiatric care, which had stagnated, in contrast to the care of the people presenting with physical conditions, which had progressed reasonably well. The next logical step is for Fiji, on which other Pacific Island nations depend for medical education, to improve its training in psychiatry so that all undergraduate students of medicine and nursing and PGDMH students can be taught modern methods of psychiatric care. This would be of major benefit to the entire region.

\title{
MENTAL \\ Mental health law profiles
} HEALTHLAW PROFILES

\author{
George Ikkos
}

Consultant Psychiatrist in Liaison Psychiatry, Royal National Orthopaedic Hospital, London, UK, emailikkos@doctors.org.uk
The East African state of Uganda has recently become the focus of international opprobrium because of proposed legislation advocating the death penalty, later reduced to life imprisonment, for homosexual relationships. In such a difficult environment some progress is nonetheless being made and the historical development of efforts to improve human rights for people who have a mental illness is clearly set out in the paper by Ssebunnya and colleagues. The importance of the World Health Organization's mental health rights advocacy and guidance stands out in relation to this (see http://www.mindbank.info), which clearly remains unfinished business.

The legislative environment is no less difficult in Sudan, where civil war has raged for decades, recently dividing the country officially in two. Saeed and colleagues seem to suggest that healthcare, including mental healthcare, has, as a result, gone backwards from a relatively advanced level. Sudanese psychiatrists now based in the UK and Ireland appear to be extending an active hand to work together with local people to overcome this catastrophic legacy for people who are mentally ill. 